\title{
Vestidos para matar: 0 sexo das guerras em Cather e Faulkner
}

Dressed to Kill: The Sex of the Wars in Cather and Faulkner

Vêtus pour tuer : le sexe des guerres chez Cather et Faulkner

\section{Paula Elyseu Mesquita}

\section{(2) OpenEdition}

\section{Journals}

Edição electrónica

URL: http://journals.openedition.org/rccs/932

DOI: $10.4000 /$ rccs. 932

ISSN: 2182-7435

\section{Editora}

Centro de Estudos Sociais da Universidade de Coimbra

Edição impressa

Data de publição: 1 Junho 2006

Paginação: 75-83

ISSN: 0254-1106

\section{Refêrencia eletrónica}

Paula Elyseu Mesquita, « Vestidos para matar: O sexo das guerras em Cather e Faulkner », Revista Crítica de Ciências Sociais [Online], 74 | 2006, colocado online no dia 01 outubro 2012, criado a 01 maio 2019. URL : http://journals.openedition.org/rccs/932 ; DOI : 10.4000/rccs.932

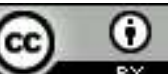




\section{PAULA ELYSEU MESQUITA}

\section{Vestidos para matar: O sexo das guerras em Cather e Faulkner}

Procedo neste ensaio a uma leitura comparada de dois romances de guerra do modernismo americano: One of Ours, de Willa Cather, e The Unvanquished, de William Faulkner. A análise debruça-se sobre a construção social do sexo e a subversão de papéis sexuais no contexto instável e destruidor do conflito militar. Focando sobretudo duas personagens, Claude Wheeler and Drusilla Hawk, pretendo analisar a guerra como o espaço escolhido pelos dois autores para testar a (in)conformidade sexual dos jovens, bem como a sua capacidade para desafiar as convenções sociais e religiosas. Uma vez que ambos se alistam voluntariamente, a guerra é apresentada tanto como lugar de destruição social como de construção individual. Interessa-me ainda discutir as implicações teóricas do facto de cada um dos autores ter escolhido, para a sua narrativa de ficção, jovens soldados de sexo oposto ao seu.

Mais conhecidos pelo seu fascínio pela herança histórica da cultura americana e pela incidência regional de uma grande parte das suas narrativas, Willa Cather e William Faulkner desenvolveram dois projectos literários e críticos inequivocamente endereçados a uma nação global e contemporânea. $\mathrm{O}$ período em que atingiram a maturidade artística (segunda e terceira décadas do século XX) foi, além do mais, do maior interesse para artistas e comentadores sociais, dada a sucessão vertiginosa de ocorrências históricas, científicas e sociais marcantes, incluindo a I Guerra Mundial, a obtenção do direito de voto por parte das mulheres, e, mais tarde, a Grande Depressão. Além disso, o processo de alteração das estruturas sociais precipitado pela vida anónima nas novas cidades industrializadas veio pôr em causa certos valores e convicções da mundivisão vitoriana. Anteriores demarcações entre a racionalidade da civilização e a irracionalidade primordial do humano começavam a ser denunciadas como precárias e rejeitadas pela cultura de classe média e alta - através da filtragem e popularização de estudos científicos - desde Darwin a Herbert Spencer e, mais tarde, Freud - como repressivas e, por isso, pouco saudáveis. Ao mesmo tempo que eram questionadas anteriores epistemologias e crenças, na verdade a nação (tal 
como a generalidade da cultura ocidental) encontrava-se ainda órfã de um sistema consistente de valores sociais com o qual pudesse enfrentar todos os novos desafios da modernidade.

O papel de autores como Cather e Faulkner nesta área é de grande interesse, uma vez que essas trepidações culturais têm forte reverberação nas suas obras e ambos mantiveram ao longo das suas carreiras uma certa ambivalência em relação ao advento da modernidade e à correspondente transição de valores morais e socioculturais. Como veremos em seguida, nas suas contemplações críticas da sociedade americana coexistem a renúncia de alguns valores basilares da cultura vitoriana média, por um lado, mas, por outro, também o repúdio do materialismo, de uma certa neurastenia e da complacência social que pareciam acompanhar o crescimento das cidades industrializadas e dominadas pelo novo capitalismo burocrático. É interessante analisar as suas posições à luz de T. J. Jackson Lears no seu marcante estudo No Place of Grace, onde identificou num certo estrato de letrados e pensadores um ninho de contracultura, que ele apelida de antimodernista, e que se manifestou entre o último quartel do século XIX e o primeiro do século XX. Como não se cansa de realçar o próprio Lears, o "antimodernismo" desses autores não equivale a uma rejeição categórica do progresso científico, industrial e económico, nem à negação de inevitáveis mudanças de natureza sociológica e cultural. Tratava-se, antes, de uma espécie de hiperconsciência minoritária dos novos rumos da civilização americana e, ao mesmo tempo, uma preocupação filosófica sobre os modos culturais emergentes dessas múltiplas e vertiginosas transformações (Lears, 1994).

Para a discussão de algumas destas tensões, em particular das transformações dos paradigmas sociossexuais que Cather e Faulkner observavam com fascínio na América do início do século XX, é oportuna a contraposição de dois dos seus textos que revelam indagações semelhantes: One of Ours, de Cather, e The Unvanquished, de Faulkner. Cada um destes romances tem como cenário uma guerra de importância central para a remodelação da identidade americana: a I Guerra Mundial, em que a América se estreia em conflitos exteriores multi-nacionais, e, no caso de The Unvanquished, a Guerra Civil Americana, que fez explodir o crescente antagonismo entre as duas principais facções culturais da nação, o Norte e o Sul. Este artigo trata da utilização do motivo da guerra como pretexto da exploração de conflitos de natureza sociossexual, em textos sobre um passado recente que interrogavam muito directamente a América contemporânea.

A obra que venceu o Pulitzer de 1922 valeu também a Willa Cather a reprovação alargada de críticos e autores da época, destacando-se a famosa 
investida de Hemingway, ${ }^{1}$ que considerava que, como mulher, Cather não estava suficientemente habilitada a escrever sobre um espaço físico e psicológico tão exclusivamente masculino. O crítico James Woodress ripostou oportunamente que nunca Leo Tolstoi havia pisado um campo de batalha (in Rosowski, 1990: 113). ${ }^{2}$ Cerca de uma década mais tarde, William Faulkner criou uma figura de soldado tão radical que chegava a ser implausível: uma southern belle em uniforme de soldado raso, cruzando em fúria as batalhas exclusivamente masculinas da Guerra Civil americana. Neste caso, porém, não só não houve reprimendas pela escolha de protagonista como o distanciamento de Faulkner em relação à realidade de guerra chegou a ser louvado como uma bênção:

Não se interessava muito pela guerra - apenas pelos seus efeitos; mas graças à sorte e ao génio, conseguiu retirar proveito literário dela. Por um lado, por ser sulista, com uma imaginação suficientemente próxima da Guerra para absorver a sua essência, mas suficientemente distante para entendê-la criticamente. E, por outro, porque tinha a acuidade de ler o significado da Guerra não nos seus heróis e batalhas, mas na consciência de um povo. (Aaron, 1973: 311; sublinhado meu)

Ou, como diria Cather, "[...] os factos não são nada, o sentimento é tudo (1953: 84).

A correcção ou precisão histórica deste retrato de uma inverosímil mulher-soldado de 1861 nunca foram seriamente questionadas. Enquanto Faulkner, fraude militar na vida real, não apenas mereceu indulgência, mas foi até elogiado pelos seus retratos de guerras em que nunca participou, Cather, nada menos empenhada na sua investigação histórica e bastante mais científica na sua abordagem, foi acusada de decalcar imagens de guerra do controverso filme de D. W. Griffith, Birth of a Nation.

$\mathrm{Na}$ verdade, apesar de a margem de manobra do autor parecer sintomaticamente maior, Cather e Faulkner empreenderam uma experiência ficcio-

\footnotetext{
${ }^{1}$ Hemingway escreveu, numa carta a Edmund Wilson datada de 1923: "The Enormous Room, de E.E. Cummings, foi o melhor livro publicado no ano passado. Alguém me disse que foi um fracasso. Mas olha o One of Ours. Prémio, boas vendas, gente a levá-lo a sério. Estiveste na guerra, não estiveste? Não está linda, aquela cena nas linhas da frente? Sabes donde é que aquilo veio? Da cena de batalha do Birth of a Nation. Coitada da mulher, tinha de ir buscar a experiência da guerra a algum lado." (Baker, 1981: 105). Todas as traduções são minhas.

2 O próprio Faulkner entendia claramente que a verdade histórica sobre a guerra é menos poderosa do que a imaginação - sobretudo a imaginação colectiva - da guerra e que é, aliás, comummente sacrificada a esta: "[...] os velhos já andavam a falar aos rapazes sobre a guerra antes de descobrirem como escrevê-la: e quem queria ser o preciosista, pôr-se a implicar com as indicações de lugar ou de cronologia, quem se importava ou insistia Vá lá, velhote, diz a verdade: viste mesmo isso? estiveste mesmo lá?" (Bayard Sartoris, in Faulkner, 1966: 107).
} 
nal surpreendentemente idêntica, utilizando a guerra como um espaço para testar a (in)conformidade sociossexual de duas jovens personagens e a sua capacidade de desafiar convenções sociais e religiosas. Hawk e Wheeler alistam-se como fervorosos voluntários e, em ambos os casos, a guerra é representada como espaço de destruição social e morte tanto como de construção individual e auto-redefinição. As duas guerras em questão revelavam-se cenários particularmente adequados ao questionamento de matrizes sociossexuais, bem como para as transformações radicais que as personagens sofrem ao longo da sua experiência militar.

O impacto que a Guerra Civil e, mais tarde, a I Grande Guerra tiveram na redefinição da identidade nacional americana é inestimável e em ambos os momentos históricos o sentido de paradoxo era avassalador. Na primeira, os americanos combatiam-se uns aos outros, divididos em facções polarizadas. A seguir, enfrentavam um inimigo que até aqui havia sido não apenas amigo, mas, literalmente, família, ligado à América por laços de imigração em massa. A convulsão social e política tornara-se a metáfora perfeita dos impulsos individuais em conflito, para a tensão binária no seio privado do eu sociossexual.

Nestes romances, Cather e Faulkner oferecem perspectivas idênticas sobre o efeito estagnador que a relativa acalmia social e abundância económica pareciam ter tido sobre a cultura e a sociedade nos períodos anteriores à guerra. Os dois autores partilhavam a mesma apreensão face à cultura de desperdício e alguma nostalgia pela tenacidade da era dos pioneiros. Drusilla designa o período pré-Guerra Civil em Jefferson pelo termo "sleep", sono enquanto Victor Morse descreve a experiência anterior de Claude no Nebraska como "a sleeping sickness" (Cather, 1968: 308). A vida nacional imediatamente anterior às guerras é representada em ambos os romances como estagnada e sem rumo, e as experiências de Claude e Drusilla até à eclosão do conflito militar são, por sinédoque, períodos de frustração paralisante. Drusilla recorda "uma vida estúpida" (Faulkner, 1966: 115), um cativeiro espiritual definido pela total dependência dos seus parentes masculinos: "A vida era um aborrecimento, entendes. Estúpida." (ibid.: 115). Sobre o seu passado no idílico Nebraska, Claude tem sentimentos de rejeição idênticos ("Não tinha tido um grande começo."), enquanto a época de batalha em França é vivida com uma intensidade sem precedentes ("não desejava estar seguro em lado nenhum, e nunca a vida tinha sido tão tentadora" [Cather, 1968: 311]).

Esses sentimentos de frustração e inquietude tinham origem na mesma dificuldade não só em se conformarem aos estereótipos sociossexuais convencionados para dois jovens da sua classe social, mas sobretudo em se 
acomodarem aos papéis designados quando eventualmente conseguem participar dessa conformidade. Os três capítulos iniciais de One of Ours oferecem um retrato confrangedor do sentido de inadequação de Claude, à volta do qual a toda a hora ecoam as palavras "queer" e "queerness", no sentido de excentricidade, de não-pertença. A sua sensibilidade delicada é lida como efeminada e indesejável num homem. A mais trivial ocorrência faz despoletar nele sentimentos de inépcia e emasculação: o pai cortando uma cerejeira, a condescendência dos seus amigos rapazes, a destemida condução da namorada. Quanto a Drusilla, apesar de pouco sabermos da vida que levava antes da guerra, é certo que até aí vivera de acordo com expectativas familiares e sociais, com vestidos de arcos e o noivado com um galante beau. Porém, na sua primeira aparição na história, está já totalmente transformada pelas circunstâncias da guerra: parece quase sair das páginas com as suas insólitas vestimentas e atitudes, tomando a seu cargo todo o tipo de tarefas físicas na propriedade dos Sartoris e até um posto militar não-oficial entre um pelotão de confederados.

Em todo o caso, os percursos metamórficos de Claude e Drusilla devem reconhecer-se como inversos. Apesar do propósito comum de sobrevivência política e de afirmação individual na comunidade, as suas estratégias performativas são diferentes, dada a diferença sexual; diferentes anatomias determinam diferentes pontos de partida no contexto social. A existência de Claude fora sempre, até aqui, penosamente conspícua e marcada por uma vivência difícil da corporalidade: sapatos de noivo profeticamente apertados, roupas que nunca assentam bem, uma cabeça cuja forma detesta. A sua adolescência é um arrastadíssimo momento de abjecção de si mesmo e de pânico do escrutínio social do seu corpo, mas, no exército, Claude compraz-se no clima de homogeneidade constante: por uma vez na vida a sua presença não se distingue ("cabeças rapadas, todos iguais" [Cather, 1968: 267]), é finalmente vista por outros como um corpo "neutro", uma incorporação de masculinidade legitimada, sem vestígios estigmáticos de feminilidade nem de qualquer modelo contestável de masculinidade. Na verdade, se agora chega a distinguir-se nalguma ocasião, é como objecto da anuência comunitária, um exemplo louvável de virilidade. Após apenas algumas semanas de treino militar já os amigos de Claude o julgam mais alto (ibid.: 248). "A guerra faz bem aos rapazes" (ibid.:243); parece ter-se feito quase instantaneamente um homem não simplesmente maior, mas melhor. Apagando todas as marcas de uma identidade não conforme aos modelos sociossexuais convencionados, ou antes, velando-as sob o verdadeiro denominador comum - a farda militar - Claude passa a identificar-se com o próprio poder, investido, nesse uniforme, da própria ideia de masculinidade nacional. 
Por sua vez, anteriormente à guerra, Drusilla parece ter tido uma existência de quase invisibilidade. Como típica belle de plantação, teria vivido o estereótipo da mulher no pedestal, com mínima margem de acção ou mostras relevantes de individualidade. Mas, quando a vemos pela primeira vez, a meio do conflito, Drusilla está já convertida numa incontornável distracção visual. Com efeito, em breve se converteu num escândalo ambulante ao juntar-se ao exército, trocando os aristocráticos vestidos por um uniforme de cabo e adoptando uma pose refractária, quase agressiva, nesta cultura concebível apenas num homem. Sublinhe-se, porém: um escândalo, mas não entre os seus companheiros de batalha. Drusilla conquista o respeito dos outros soldados - em parte, talvez, como parente de John Sartoris e como mulher de classe alta. Mas, sem dúvida, também por ser uma combatente destemida. Na verdade, ironicamente, serão as mulheres da comunidade a rejeitarem a sua nova imagem e a forçá-la a regressar aos vestidos assim que termina o conflito. Encontramos um padrão idêntico no mundo de Claude, que é lamentado e ridicularizado pelos concidadãos de Frankfort, mas admirado pelos companheiros de combate.

Cather e Faulkner partilhavam a mesma forte convicção de que este tipo de conflitos fazia emergir surgir um novo sentido de si mesmo, no sentido em que a ruptura e a privação evidenciam obliquamente as limitações, capacidades e aspirações individuais. A identidade dos indivíduos, tal como a das nações, evolui e é modelada em disputas permanentes consigo mesmo e com o outro. E se a guerra servia como plano metafórico de tensões sociossexuais, o corpo fardado seria o campo de batalha desse pleito.

Num plano pessoal, tanto Cather como Faulkner revelaram desde cedo um forte sentido histriónico de si mesmos e um interesse particular em máscaras e disfarces. A excêntrica jovem Cather apresentava-se constantemente em público vestida de rapaz, na personagem de "William" ou "Billy" Cather, pretenso médico que provocava os seus interlocutores com as mais surpreendentes tiradas chauvinistas. Roupagens masculinas identificadas com modelos hegemónicos de masculinidade também desde a juventude exerceram o seu fascínio sobre Billy Faulkner (desde as fardas militares aos fatos de montar a cavalo que algumas décadas mais tarde encomendava especialmente de Inglaterra). Também ele visivelmente vivia o drama da auto-representação, e, tal como Cather, procurou reinventar a imagem da sua masculinidade com todo o tipo de adereços que se ofereciam (roupas, casas, cavalos, espingardas). Com efeito, ao criar as personagens de Claude Wheeler e, muito particularmente, Victor Morse (que Claude admira justamente pelos seus talentos camaleónicos [Cather, 1968: 331]), Cather apresentou inadvertidamente na sua ficção as dificuldades reais 
vividas por Faulkner nessa mesma altura. Faulkner fez o treino de piloto de avião durante a I Grande Guerra e alimentava as mais altas expectativas para o seu futuro como piloto da RAF e, ulteriormente, como veterano de guerra. No final, porém, os seus préstimos de piloto qualificado nunca chegaram a ser requisitados. Tal como Victor Morse, também Faulkner chegara a ensaiar um sotaque britânico com o seu amigo Phil Stone. Escrevera certa vez aos seus pais, em carta de 7 de Junho de 1918: "Nunca hei-de fazer nada de mim mesmo, mas com esta história fico garantido depois de a guerra terminar." (Faulkner, 2000: 41-42). Tal como Victor e Claude, acalentara esperanças sobre uma guerra que a propaganda tornara suspeitamente auspiciosa: "tirava um rapazito de uma vilória, dava-lhe uns ares e um andar janota" (Cather, 1968: 375). Efectivamente, Faulkner não se referia nessa carta a mera estabilidade financeira. Tal como Cather escolhera emular o seu prestigiado parente masculino William Cather, Faulker entendeu a guerra como uma oportunidade de se modelar à epítome de masculinidade do cavalier associada ao seu legendário avô William C. Faulkner, coronel da Confederação.

Cather não podia efectivamente mudar de sexo, nem Faulkner reclamar honestamente honras de veterano. A alternativa revelou-se para ambos sob a forma de disfarces e auto-estilização. Adequando a realidade às suas idealizações de identidade sociossexual, elegeram os seus modelos reverendos de masculinidade, vivendo ela durante um longo período na persona do médico, e ele exibindo as suas falsas mazelas da guerra, coxeando por Oxford, Miss., de uniforme militar e apoiado numa bengala. Na vida como na ficção, estavam ambos fascinados pela natureza performativa da identidade sociossexual, tal como Judith Butler viria a descrever o fenómeno: concomitantemente, uma consequência, um instrumento e uma sátira das relações sociais de poder (Butler, 1999: 173).

Os corpos de Drusilla e de Claude, por exemplo, são focos de perpétuo desconforto, tanto por parte deles mesmos como daqueles que os observam. À medida que a performatividade sociossexual e a incorporação do poder se revelam como estratégias de sobrevivência cultural, a anatomia sexual torna-se problemática, uma nova plataforma de conflito e transformação. O uniforme de Claude fá-lo parecer mais alto, e também amplifica a sua importância política no seio da comunidade de Frankfort. Por outro lado, o derrotado John Sartoris tenta reconfortar Drusilla quando esta resiste a abandonar as suas roupas de homem, perguntando-lhe: "O que é um vestido?" (Faulkner, 1966: 30); mas Drusilla sabe bem que um vestido é a reinstalação do status quo pré-Guerra Civil. Forçada a vestir os vestidos de belle quando a guerra termina, será eventualmente derrotada pelo facto de 
a sua velha indumentária anunciar a outros o restabelecimento da ordem sociossexual anterior. Se as guerras em que participam são, por um lado, contextos de destruição devastadora, não é menos verdade que são ambientes muito menos dominados por constrições morais e religiosas e é neste sentido que se apresentam oportunidades excepcionais para a reformulação individual da performance sociossexual.

No final, por diferentes razões, as quebras com a convenção acabam por se revelar pouco definitivas, o que reflecte a fluidez e hesitação cultural também da época em que os romances foram produzidos. Apesar da corrente crítica que elege a figura de Drusilla como uma espécie de pré-feminista, sem medo de usurpar a esfera masculina, na verdade as suas motivações são meramente individualistas. A sua experiência política está condenada desde o início, não apenas pela sua capacidade de reconhecer a iniquidade insustentável da hierarquia social, mas porque não se trata efectivamente de um projecto político e sim de mera aspiração individual. Apesar de o seu esforço incorporar um modelo sociossexual politicamente agitador, ela nunca demonstra qualquer sentido de grupo, nem se mostra capaz de empatia pela experiência de outras mulheres, quer brancas, quer negras. O mesmo acaba por suceder com Claude, um New Man embriónico que sucumbe ao ideal primitivista do ideal de masculinidade herdado do pioneirismo. Comprometido por uma sensibilidade emocional que complica a sua vida social, distinguindo-o como "estranho", acaba por emular um modelo hegemónico de masculinidade, isto é, acaba por imitar uma identidade, tornando-se outro de si mesmo. Por outras palavras, a sua rejeição de uma sensibilidade primária identificada como efeminizante é já uma forma de suicídio psicológico, replicada, ou antes completada pela morte física voluntária em combate.

\section{Referências bibliográficas}

Aaron, Daniel (1973), The Unwritten War. American Writers and the Civil War. London: Oxford University Press.

Baker, Carlos (1981) Ernest Hemingway. Selected Letters, 1917-1961 New York: Scribner's.

Butler, Judith (1999 [1990]), Gender Trouble. Feminism and the Subversion of Identity. New York and London: Routledge.

Cather, Willa (1953), Willa Cather on Writing. Critical Studies on Writing as an Art. New York: Alfred A. Knopf.

Cather, Willa (1968), One of Ours. New York: Alfred A Knopf [1922].

Faulkner, William (1966), The Unvanquished. New York: Vintage Books [1934]. 
Faulkner, William (2000) Thinking of Home: William Faulkner's Letters to His Mother and Father 1918-1925. Org. James G. Watson. New York and London: W. W. Norton and Company.

Lears, T. J. Jackson, (1994), No Place of Grace. Antimodernism and the Transformation of American Culture. 1880-1920. Chicago: The University of Chicago Press.

Rosowski, Susan J. (org.) (1990), Cather Studies (Volume 1). Lincoln and London: University of Nebraska Press.

Woodress, James, Willa Cather: Her Life and Art (New York: Pegasus), 1970. 